\title{
Avoidance High-Frequency Chattering Second-Order Sliding Mode Controller Design: Buck Converter in Wind Power System
}

\author{
Yigeng Huangfu, ${ }^{1}$ Ruiqing Ma, ${ }^{1}$ and Abdellatif Miraoui ${ }^{2}$ \\ ${ }^{1}$ School of Automation, Northwestern Polytechnical University, Xi'an 710072, China \\ ${ }^{2}$ University of Technology Belfort-Montbeliard, 90000 Belfort, France
}

Correspondence should be addressed to Yigeng Huangfu, yigeng@nwpu.edu.cn

Received 15 August 2012; Accepted 8 October 2012

Academic Editor: Fuli Zhang

Copyright (C) 2012 Yigeng Huangfu et al. This is an open access article distributed under the Creative Commons Attribution License, which permits unrestricted use, distribution, and reproduction in any medium, provided the original work is properly cited.

\begin{abstract}
This paper mainly discussed a method of high-frequency second-order sliding mode control for Buck converter in wind power systems. Because the wind energy of nature is always unpredictable and intermittent, the robust control such as sliding mode control is adopted in past literatures. In order to remove the high frequency chattering problem when the traditional sliding mode achieves convergence, the second order sliding mode algorithm is reviewed firstly. Meanwhile, the Buck converter taken as a step-down converter is usually adopted in wind power system, because of its simple structure and good linearity. Under those conditions, the second order sliding mode controller is designed based on Buck converter, especially in high-power wind generation system. The experimental results illustrate that the theory of second order sliding mode can be used in high-power Buck converter. It provides one novel avoidance high frequency chattering method for the technology development of new energy generation system.
\end{abstract}

\section{Introduction}

Conventional energy resources may run out of in the following few decades, especially from fossil energy could lead to the energy shortage in the world. Moreover, the energy consumption is increased dramatically in recent years. The renewable energy sources, such as solar, wind, or ocean wave energy, are considered to be the future energy solutions. Thanks to the extensive research in renewable energy field, those energies can be exploited more and more easily and properly [1-3].

Among the renewable resources, the wind energy is gaining greater visibility during the last several years as a convenient and promising energy source in the future [4]. The application of wind energy is divided into two aspects. One is off-grid wind power station with the battery as energy storage component, and the other is connectto-grid wind turbine. In many applications, such as small villages or islands power station, the off-grid wind power generation system provides an excellent energy solution. The key problem of this kind of energy production systems is that they are unstable energy sources due to their primary source in nature.

Thus, an energy storage component is usually added to form a hybrid energy system. In such a system, the suitable power converter plays an important role in energy conversion and management system.

Generally speaking, these converters should be adaptive for wider wind speed range in order to improve the system performance. In a wind generation system, two types of converter can be usually found: a primary AC/DC converter connected directly to the wind turbine generator and a secondary DC/DC converter connected to the load. As known, the nonisolated DC/DC Buck converter is usually used in lower power system [5-7]. For robustness improvement, the sliding mode technology is widely used.

Well known to all is that the PI control has become classical method in engineering applications owing to its simple structure and universality. The switch property of power device in converter makes the converter becomes discrete time-variable system. Thus, the sliding mode control holds strong suitability for Buck converter [8]. However, 


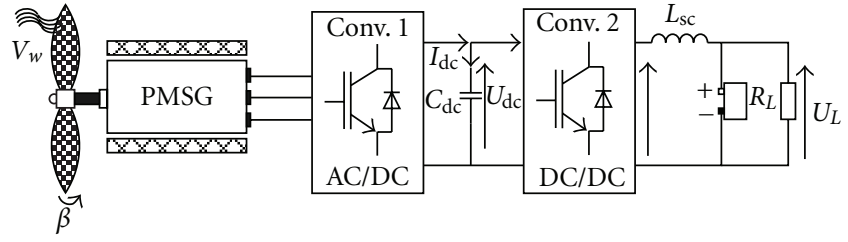

FIGURE 1: Off-grid wind power generation system.

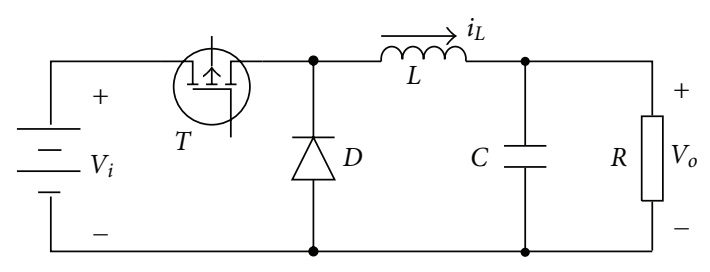

FIgURE 2: Buck converter topology.

traditional sliding mode control has the drawback of chattering phenomenon owing to its discrete control law. In order to overcome this disadvantage, a high frequency second order sliding mode control algorithm was proposed by Bartolini et al. [9] and Levant et al. [10].

A second sliding mode controller for Buck converter is designed in this paper when the system relative degree equals $r=2$. By taking the derivative of sliding mode variable $s$ continuously, until the control input $u$ appears, it makes discrete control law acts on the second order sliding mode manifold $\dot{s}$, so that the lower sliding mode manifold $s$ avoids high frequency chattering. The experiment results illustrate that the system holds good performance, especially in highpower Buck converter.

This paper is organized as follows. In Section 2, the related system structure and mode of Buck converter are given. In Section 3, the second order sliding mode method based on the Buck converter is presented. The experimental results of the algorithm proposed in this paper with Buck converter for wind power system are also presented in Section 4. Finally, our work of this paper is summarized in Section 5.

\section{System Structure and Mode of Buck Converter}

In general, six parts can be distinguished in an off-grid wind power generation system. They are wind turbine, permanent magnet synchronous generator (PMSG), AC/DC rectifier, DC/DC converter, storage battery, and load. The structure of the system is presented in Figure 1.

The wind energy in nature drives the turbine to whirl. From where the PMSG produces the AC electrical energy, whose frequency is variable, depends on the random wind speed in the nature under the external torque. Through the $\mathrm{AC} / \mathrm{DC}$ rectifier, the DC electrical energy with alterable amplitude is obtained. In comparison with conventional Buck converter, the wider input voltage range is a novel challenge for the converter design. For system performance consideration, the maximum power point tracking (MPPT) technology control method is used $[11,12]$, in order to ensure a stable DC output for storage battery and load.

The topology of Buck converter is shown in Figure 1. T is switch, $L$ is inductance, $C$ is capacitance, $D$ is freewheel diode, and $R$ is load resistance. $i_{L}$ is the current of inductance $L, V_{i}$ is input voltage, and $V_{o}$ is output voltage.

The Buck converter has double modes, which are conduction and shutoff of switch. From Figure 2, according to the KCL and KVL, there should be

$$
\begin{gathered}
C \frac{d V_{o}}{d t}+\frac{V_{o}}{R}=i_{L}, \\
L \frac{d i_{L}}{d t}+V_{o}=V_{i} \cdot \Delta .
\end{gathered}
$$

The state function of Buck converter is rewritten by

$$
\left[\begin{array}{l}
\frac{d V_{o}}{d t} \\
\frac{d i_{L}}{d t}
\end{array}\right]=\left[\begin{array}{cc}
\frac{-1}{R C} & \frac{1}{C} \\
\frac{-1}{L} & 0
\end{array}\right]\left[\begin{array}{c}
V_{o} \\
i_{L}
\end{array}\right]+\left[\begin{array}{c}
0 \\
\frac{\Delta}{L}
\end{array}\right] V_{i}
$$

where $\Delta$ is duty cycle. Let $x=\left[x_{1}, x_{2}\right]^{T}=\left[V_{o}, i_{L}\right]$, and let the control input of system $u=V_{i}$; then the above equation can be rewritten by

$$
\left[\begin{array}{l}
\dot{x}_{1} \\
\dot{x}_{2}
\end{array}\right]=\left[\begin{array}{cc}
k_{1} & k_{2} \\
k_{3} & 0
\end{array}\right]\left[\begin{array}{l}
x_{1} \\
x_{2}
\end{array}\right]+\left[\begin{array}{c}
0 \\
k_{4}
\end{array}\right] u,
$$

where $k_{1}=-1 / R C+\delta k_{1}, k_{2}=1 / C+\delta k_{2}, k_{3}=1 / L+\delta k_{3}$, and $k_{4}=\Delta / L+\delta k_{4}$. In the expressions, the $\delta k_{i}(1 \leq i \leq 4)$ represents the uncertainty part of system parameters.

\section{Second Order Sliding Mode}

It is necessary to review the principle of second order sliding mode. The sliding mode control is known to be a robust approach to solve the control problems of nonlinear systems. Robustness properties against various kinds of uncertainties such as parameter perturbations, external disturbances, and measurement errors can be guaranteed. However, this control strategy has a main drawback: the well-known chattering phenomenon [13]. In order to reduce the chattering, an approach called second order sliding mode (SOSM) has been proposed, whose convergence trajectory curve on $s$ and $s^{\prime}$ is shown in Figure 3. Some literatures also call it as the dynamic sliding mode control (DSM) [14].

Without losing generality, considering a state equation of single input nonlinear system as

$$
\begin{gathered}
\dot{x}=f(x)+g(x) u, \\
y=s(x, t),
\end{gathered}
$$

where $x \in R^{n}$ is system state variable, $t$ is time, $y$ is output, and $u$ is control input. Here, $f(x), g(x)$, and $s(x)$ are smooth function. The control objective is making output function $s \equiv 0$. 


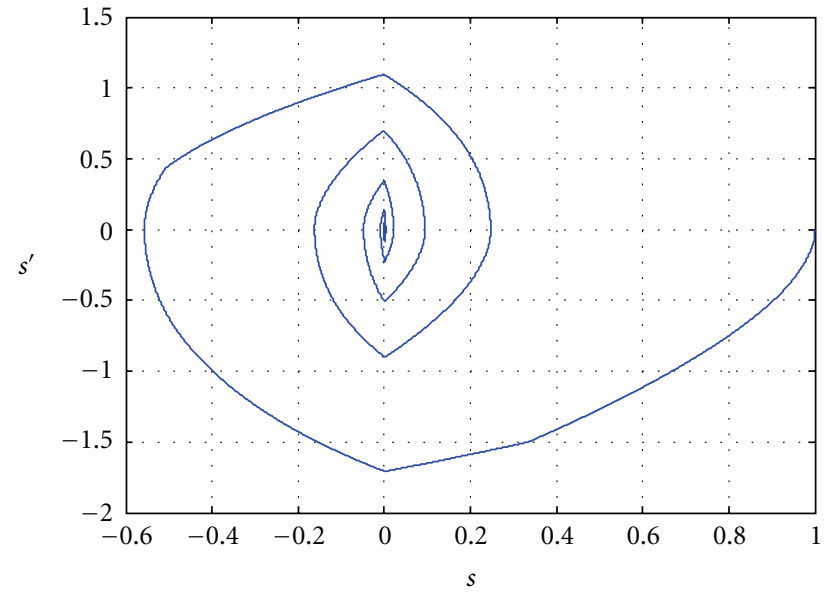

FIGURE 3: The convergence trajectory of twisting algorithm.

Differentiating the output variables continuously, we can get every order derivative of $s$. According to the conception of system relative degree, there are two conditions:

(I) Relative degree $r=1$, if and only if $(\partial / \partial u) \dot{s} \neq 0$.

(II) Relative degree $r \geq 2$, if $(\partial / \partial u) s^{(i)}=0(i=1,2, \ldots r-$ $1)$ and $(\partial / \partial u) s^{(r)} \neq 0$.

If the relative degree $r=1$, traditional sliding mode control can be used to design controller. Else, it needs to design a second order sliding mode controller. Second order sliding mode control is able to eliminate chattering.

Supposing system relative degree equals 1 and differentiating sliding mode variable twice continuously, then

$$
\begin{aligned}
\dot{s}=\frac{\partial}{\partial t} s(x, t)+\frac{\partial}{\partial x} s(x, t)[f(x)+g(x) u], \\
\ddot{s}=\underbrace{\frac{\partial}{\partial t} \dot{s}(x, t)+\frac{\partial}{\partial x} \dot{s}(x, t)[f(x)+g(x) u]}_{\varphi(x)}+\underbrace{\frac{\partial}{\partial u} \dot{s}(x, t) \dot{u}}_{\gamma(x)} \\
=\varphi(x)+\gamma(x) \dot{u} .
\end{aligned}
$$

In order to achieve this aim of eliminating chattering, the $\dot{u}$ derivative of control input $u$ is made as actual control variable. The discontinuous control law $\dot{u}$ will drive sliding mode variable $s=0$ in the second order sliding mode surface $S^{2}$. In this way, chattering is eliminated [15].

Definition 1. Supposing given sliding mode variable is $s(x, t)$, second order sliding mode surface (or called sliding mode manifold) is defined as

$$
S^{2}=\{x \in X \mid s(x, t)=\dot{s}(x, t)=0\} \quad x \in R^{n} .
$$

To illustrate the tightness of control algorithm, the following conditions must be met $u$ is continuous and bounded norm function:

$$
\|f(x)\|_{2},\|g(x)\|_{2} \text { are bounded, } \quad \gamma(x)>0 .
$$

In meeting the above bounded conditions, there must be positive constants $\Gamma_{m}, \Gamma_{M}$, and $\Phi$ so that

$$
\begin{gathered}
0<\Gamma_{m} \leq \gamma(x) \leq \Gamma_{M}, \\
|\varphi(x)| \leq \Phi .
\end{gathered}
$$

A second order sliding mode algorithm is called twisting, which shuttle among the double differentiation manifold so that system can converge into zero within finite time [16]. If the relative degree of system equals 1 , the detail control law is

$$
\dot{v}(t)= \begin{cases}-u & |u|>u_{\max } \\ -V_{m} \operatorname{sign}(s) & s \dot{s} \leq 0 ;|u| \leq u_{\max } \\ -V_{M} \operatorname{sign}(s) & s \dot{s}>0 ;|u| \leq u_{\max } .\end{cases}
$$

Likewise, if the relative degree equals to 2 ,

$$
v(t)= \begin{cases}-V_{m} \operatorname{sign}(s) & s \dot{s} \leq 0 \\ -V_{M} \operatorname{sign}(\dot{s}) & s \dot{s}>0 .\end{cases}
$$

The sufficient condition of the sliding mode surface convergence into origin with finite time is

$$
\begin{gathered}
0<V_{m}<V_{M}, \\
\frac{\Phi}{\Gamma_{m}}<V_{m}, \\
\Gamma_{m} V_{M}-\Phi>\Gamma_{M} V_{m}+\Phi .
\end{gathered}
$$

The convergence trajectory of twisting algorithm is shown in Figure 2. It converges to origin with finite time asymptotically.

\section{Controller Design}

Suppose all the variables can be measured. The sliding mode surface is chosen as

$$
s=x_{1}-x_{1 \text { ref }}=0,
$$

where $x_{1 \text { ref }}$ is the reference of output voltage. Take the derivate of $s$, then

$$
\dot{s}=\dot{x}_{1}-\dot{x}_{1 \mathrm{ref}}=k_{1} x_{1}+k_{2} x_{2}-\dot{x}_{1 \mathrm{ref}} .
$$

The control input $u$ does not appear in (13). So take the derivative of $\dot{s}$ until $u$ appears out.

$$
\ddot{s}=\left(k_{1}^{2}+k_{2} k_{3}\right) x_{1}+k_{1} k_{2} x_{2}+k_{2} k_{4} u-\ddot{x}_{1 \text { ref. }} .
$$

Thus, the system relative degree is 2 . The twisting algorithm (10) is used now. Remarkably, the choice of sliding mode surface is not unique. For example, the following sliding mode surface is selectable:

$$
s=\dot{x}_{1}-\dot{x}_{1 \text { ref }}+\lambda\left(x_{1}-x_{1 \mathrm{ref}}\right)=0 .
$$

In (15), $\lambda$ is a positive constant, which should satisfy Hurwitz polynomial $P(z)=\dot{z}+\lambda z$. When we derive $s$, the control input $u$ first appears in expression. So the relative degree equals 1 . The corresponding algorithm (9) can be used. In this paper, the algorithm of the relative degree equaling 2 is adopted. 


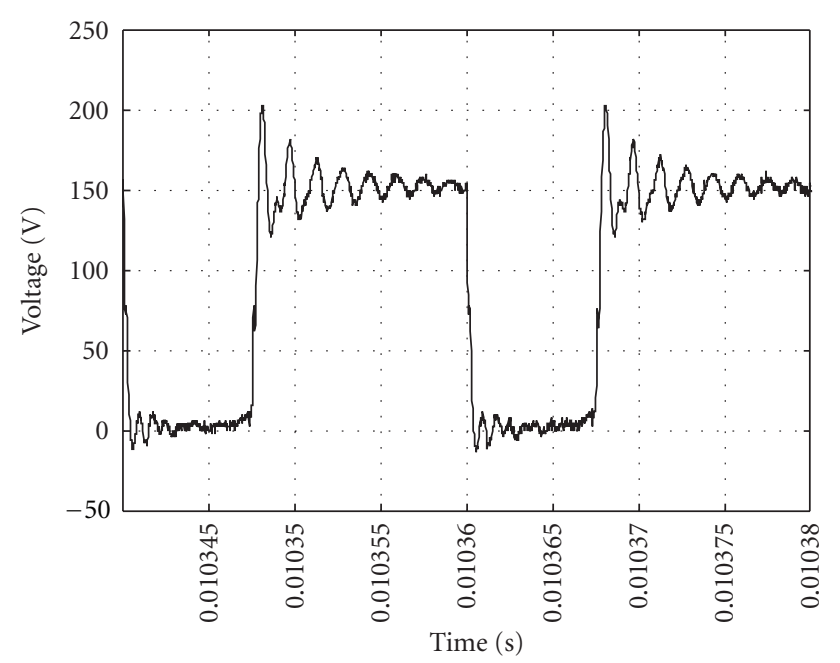

FIGURE 4: The voltage on MOSFETs with sliding mode.

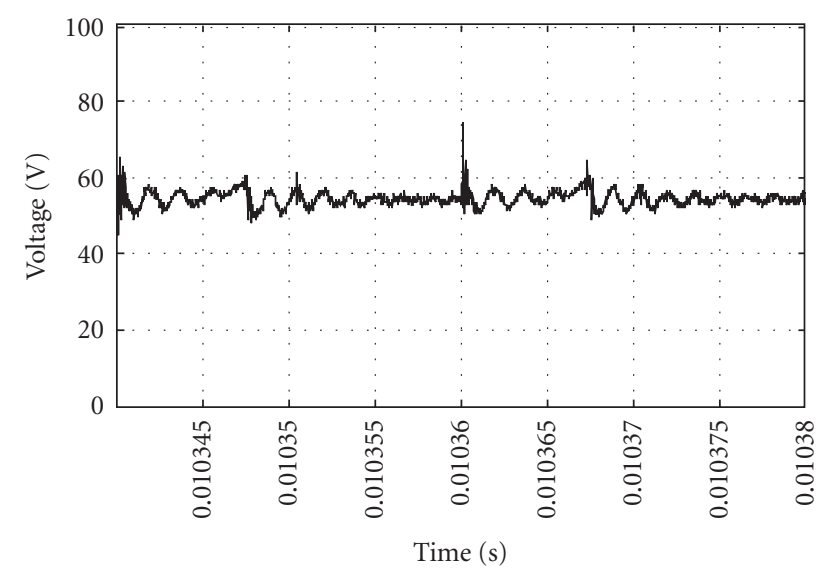

FIGURE 5: The output voltage of system with sliding mode.

TABLE 1: Experimental parameters.

\begin{tabular}{lccc}
\hline Name & Notation & Value & Unit \\
\hline Inductance & $L$ & 200 & $\mathrm{mH}$ \\
Capacitance & $C$ & $470 \times 4$ & $\mathrm{uF}$ \\
Input voltage & $V_{i}$ & $<300$ & $\mathrm{~V}$ \\
Resistance & $R$ & 10 & $\Omega$ \\
Switch freq. & $f_{s}$ & $20 \mathrm{k}$ & $\mathrm{Hz}$ \\
Battery & $Q$ & $200 \times 4$ & $\mathrm{Ah}$ \\
\hline
\end{tabular}

\section{Experimental Result}

In the experiment, the elements parameters of the Buck converter are displayed in Table 1. For testing the second sliding mode controller, in the model of Buck converter, the second order sliding mode controller's parameters are $V_{m}=70, V_{M}=200$. The experimental parameters of control platform are shown in Table 1 in detail.

Figure 4 shows the voltage between drain and source using traditional sliding mode control method. From this figure, the peak voltage is up to $200 \mathrm{~V}$. When the MOSFET

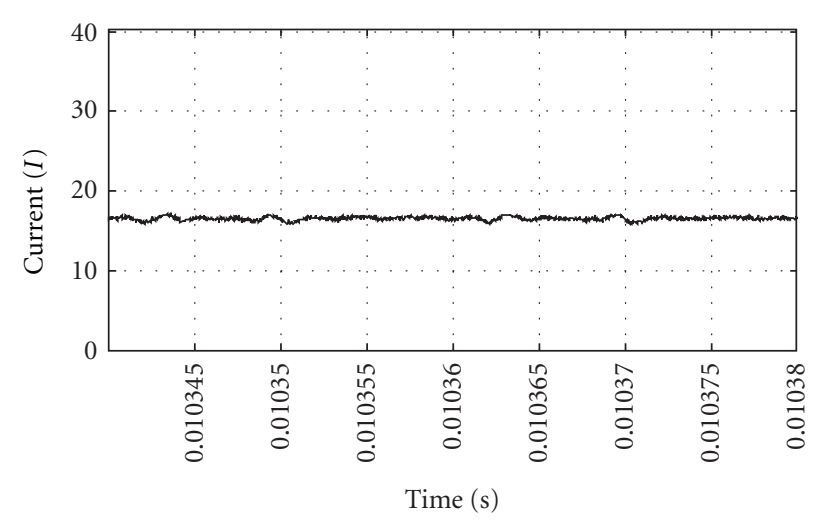

FIGURE 6: The output current of system with sliding mode.

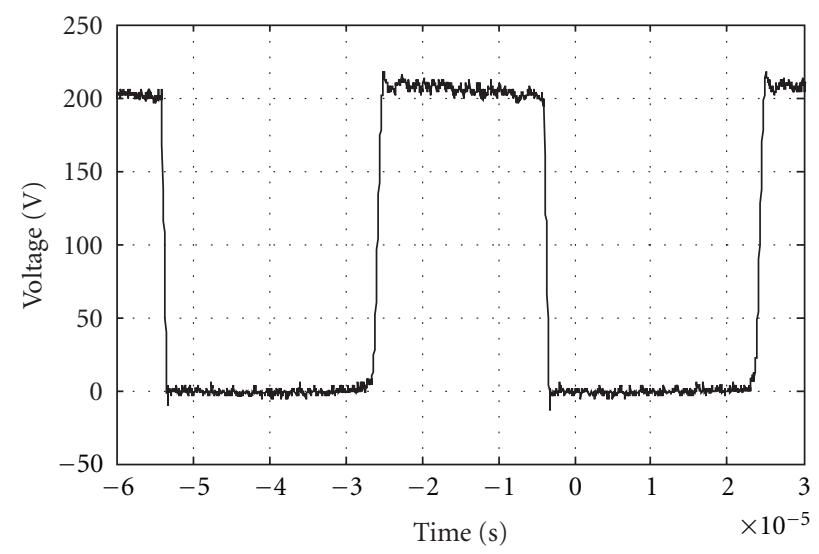

FIgure 7: The voltage on MOSFETs with second order sliding mode.

works in conducting state, there is obvious chattering due to the nonlinear stray parameters.

For the output voltage of system, high frequency PWM chopper produces a number of ripples, sometimes called chattering in control, in Figure 5.

From Figure 6, the charge current nearly achieves at 18A using the sliding mode control. In this case, the output power of system is about $1000 \mathrm{~W}$.

Figure 7 shows the voltage between drain and source. From this figure, it can be inferred that the bus voltage is up to $200 \mathrm{~V}$. It means the second order sliding mode works well in high-power system.

In comparison with the traditional control method in Figure 5, Figure 8 displays the output voltage of system using sliding mode control. It is easy to say that the ripple or chattering voltage is removed obviously.

Actually, the Buck converter is connected with a battery and the load usually. The output voltage and current are displayed in Figures 8 and 9. And the output voltage reaches over $70 \mathrm{~V}$ more than battery's rated voltage $48 \mathrm{~V}$, owing to the float charge condition. Meanwhile, the output current is near to $23 \mathrm{~A}$. In this way, the total power achieves $1600 \mathrm{~W}$ using this method. 


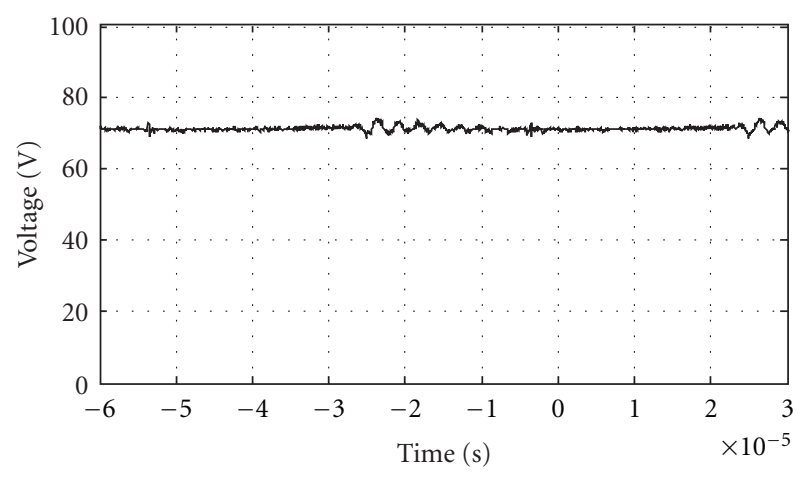

FIGURE 8: The output voltage of system with second order sliding mode.

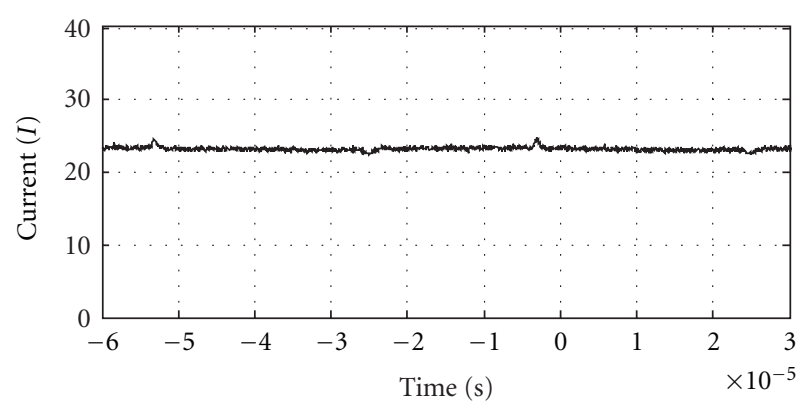

FIGURE 9: The output current of system with second order sliding mode.

\section{Conclusions}

Above all, the second order sliding mode control diverts the discrete control law onto the higher order sliding mode manifold, so that the first sliding mode surface becomes smoother. Thus, it removes the high frequency chattering phenomenon which exists in the traditional sliding mode.

In this paper, the proposed method is successfully used in high-power Buck converter for wind power system. The experimental results illustrate that the second order sliding mode can be applied in actual engineering project. This technology will propel the development of new energy generation systems.

\section{Acknowledgments}

This work was supported in part by NSFC under Grant no. 51177135 and the Key Project of Natural Science Foundation of Shaanxi Province (2011GZ013).

\section{References}

[1] N. Lior, "Energy resources and use: the present situation and possible paths to the future," Energy, vol. 33, no. 6, pp. 842857, 2008.

[2] P. D. Lund, "Effects of energy policies on industry expansion in renewable energy," Renewable Energy, vol. 34, no. 1, pp. 5364, 2009.
[3] P. A. Østergaard, "Reviewing optimisation criteria for energy systems analyses of renewable energy integration," Energy, vol. 34, no. 9, pp. 1236-1245, 2009.

[4] M. Hoogwijk, B. de Vries, and W. Turkenburg, "Assessment of the global and regional geographical, technical and economic potential of onshore wind energy," Energy Economics, vol. 26, no. 5, pp. 889-919, 2004.

[5] V. Mummadi, "Fourth order buck converter for photovoltaic maximum power point tracking applications," in Proceedings of the IEEE International Conference on Sustainable Energy Technologies (ICSET'08), pp. 295-300, Singapore, November 2008.

[6] S. K. Mazumder, M. Tahir, and S. L. Kamisetty, "Wireless PWM control of a parallel DC-DC buck converter," IEEE Transactions on Power Electronics, vol. 20, no. 6, pp. 12801286, 2005.

[7] H. F. Bilgin, K. N. Köse, G. Zenginobuz et al., "A unitypower-factor buck-type PWM rectifier for medium/highpower DC motor drive applications," IEEE Transactions on Industry Applications, vol. 38, no. 5, pp. 1412-1425, 2002.

[8] S. A. Bock, J. R. Pinheiro, H. Gründling, H. L. Hey, and H. Pinheiro, "Existence and stability of sliding modes in bidirectional DC-DC converters," in Proceedings of the IEEE 32nd Annual Power Electronics Specialists Conference, pp. 1277-1282, Vancouver, Canada, June 2001.

[9] G. Bartolini, A. Ferrara, A. Pisano, and E. Usai, "On the convergence properties of a 2-sliding control algorithm for nonlinear uncertain systems," International Journal of Control, vol. 74, no. 7, pp. 718-731, 2001.

[10] A. Levant, A. Pridor, J. Z. Ben-Asher, R. Gitizadeh, and I. Yaesh, "Aircraft pitch control via second-order sliding technique," Journal of Guidance, Control, and Dynamics, vol. 23, no. 4, pp. 586-594, 2000.

[11] K. Y. Lo, Y. M. Chen, and Y. R. Chang, "MPPT battery charger for stand-alone wind power system," IEEE Transactions on Power Electronics, vol. 26, no. 6, pp. 1631-1638, 2011.

[12] Y. Y. Hong, S. D. Lu, and C. S. Chiou, "MPPT for PM wind generator using gradient approximation," Energy Conversion and Management, vol. 50, no. 1, pp. 82-89, 2009.

[13] W. Slotine and J. E. Li, Applied Nonlinear Control, Prentice Hall, Englewood Cliffs, NJ, USA, 1991.

[14] A. J. Koshkouei, K. J. Burnham, and A. S. I. Zinober, "Dynamic sliding mode control design," IEE Proceedings of Control Theory and Applications, vol. 152, no. 4, pp. 392-396, 2005.

[15] Y. Huangfu, S. Laghrouche, W. Liu, and A. Miraoui, "A chattering avoidance sliding mode control for PMSM drive," in Proceedings of the 8th IEEE International Conference on Control and Automation (ICCA'10), pp. 2082-2085, Xiamen, China, June 2010.

[16] A. Levant, "Higher-order sliding modes, differentiation and output-feedback control," International Journal of Control, vol. 76, no. 9-10, pp. 924-941, 2003. 

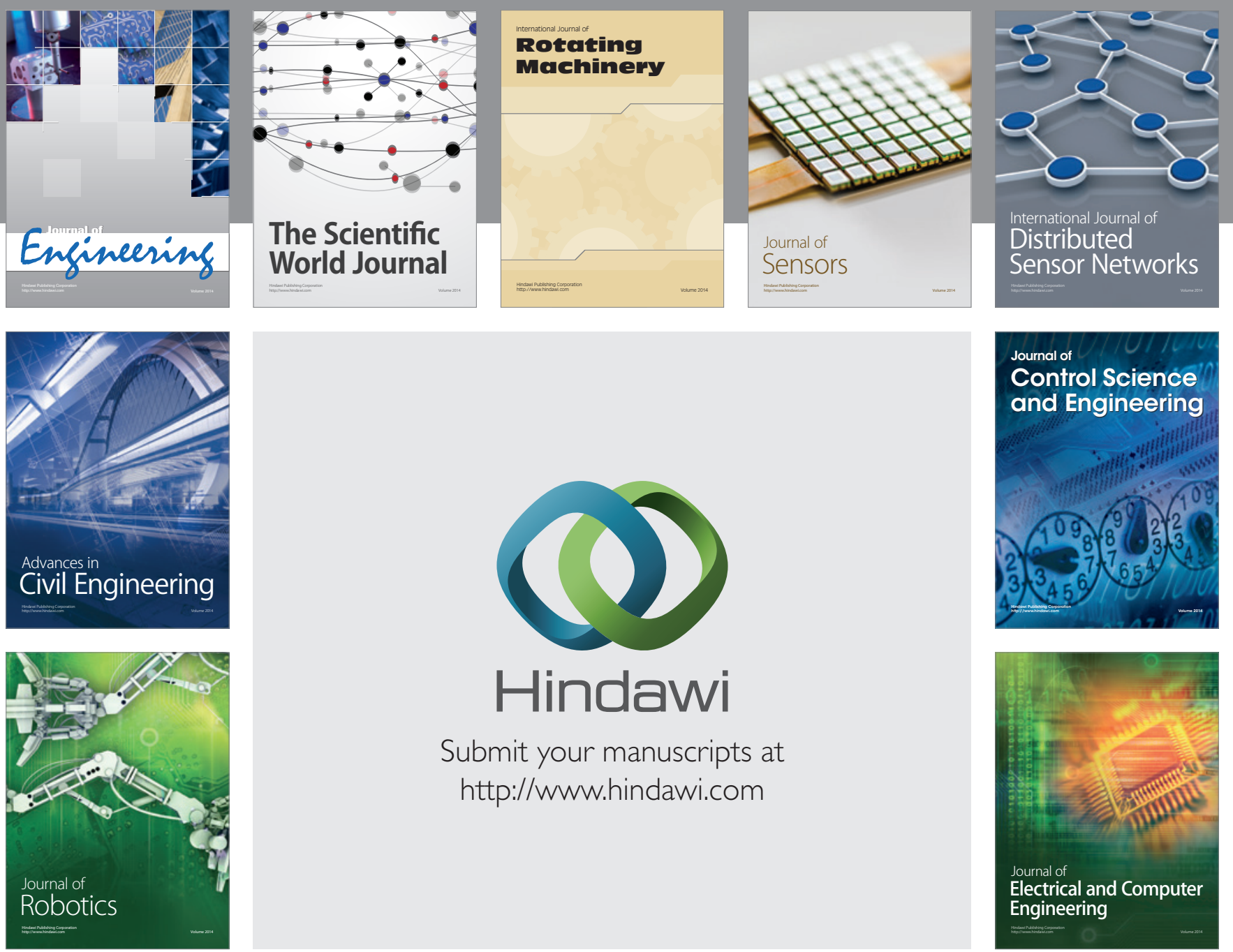

Submit your manuscripts at

http://www.hindawi.com
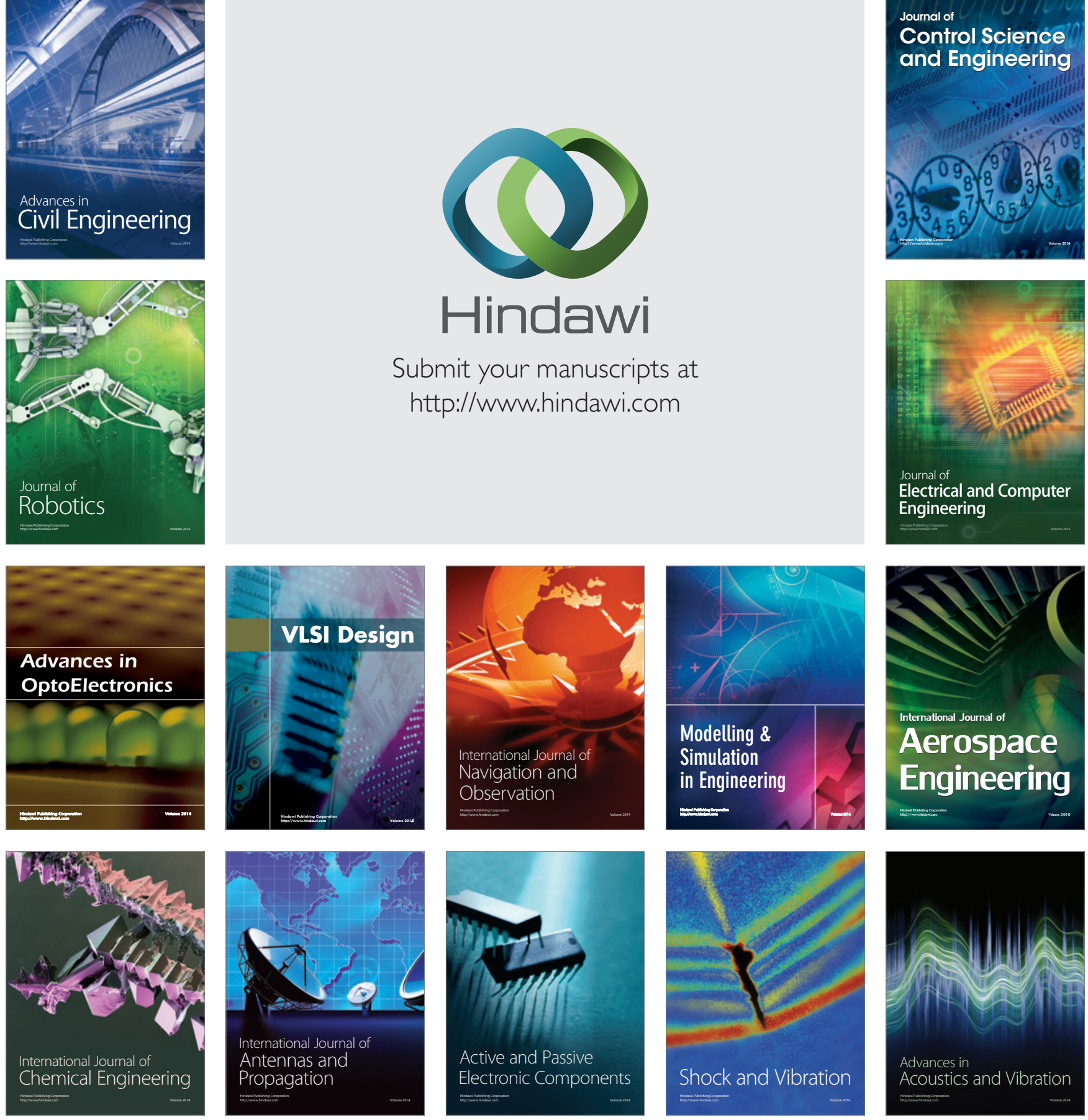